\begin{tabular}{|l|l|l||}
\hline \multicolumn{2}{|c|}{ PublisherInfo } \\
\hline \hline PublisherName & $:$ & BioMed Central \\
\hline \hline PublisherLocation & $:$ & London \\
\hline \hline PublisherImprintName & $:$ & BioMed Central \\
\hline \hline
\end{tabular}

\title{
Autoantibody detection by arrays
}

\begin{tabular}{||l|l|l||}
\hline \multicolumn{2}{|c|}{ ArticleInfo } \\
\hline \hline ArticleID & $:$ & 267 \\
\hline \hline ArticleDOI & $:$ & $10.1186 /$ ar-2002-76800 \\
\hline \hline ArticleCitationID & $:$ & 76800 \\
\hline \hline ArticleSequenceNumber & $:$ & 20 \\
\hline \hline ArticleCategory & $:$ & Paper Report \\
\hline \hline ArticleFirstPage & $:$ & 1 \\
\hline \hline ArticleLastPage & $:$ & 3 \\
\hline \hline & & RegistrationDate : 2002-4-9 \\
& $:$ & Received \\
ArticleHistory & & Accepted 2002-4-9 \\
& $:$ 2002-5-10 \\
\hline \hline ArticleCopyright & $:$ & Biomed Central Ltd2002 \\
\hline \hline ArticleGrants & $:$ & \\
\hline \hline
\end{tabular}




\begin{tabular}{|l|l|l||}
\hline ArticleContext & $:$ & 130754411 \\
\hline
\end{tabular}

Martin Aringer, ${ }^{\text {Aff1 }}$

Aff1 University of Vienna, Austria

\section{Keywords}

autoantibodies, lupus, rheumatoid arthritis, scleroderma, Sjogren

\section{Context}

A wide variety of autoantibodies are of diagnostic importance in rheumatic diseases. In addition to this clinical aspect, autoantibody patterns and their development in early disease help improve our understanding of disease pathogenesis. While microarrays are already widely used for nucleic acid screening, a related technique may be very useful for rapidly detecting multiple autoantibodies with small amounts of serum.

\section{Significant findings}

With a robotic arrayer, 1152 feature arrays were fabricated that carried 196 distinct autoantigens in replicate sets on poly-L-lysine coated glass slides. These arrays were tested with well-characterized sera of patients with autoimmune diseases, mixtures of these sera and sera of healthy individuals. The autoantibodies were scanned after being made visible with fluorochrome-labeled secondary reagents specific for different immunoglobulin subclasses. By this approach, antibodies to most autoantigens were detectable, including antibodies to post-translational modifications and to linear peptides, but there were some exceptions (e.g. for Sm proteins). The technique was shown to be specific, more sensitive than ELISA, and capable of quantifying autoantibody concentrations. In an alternative approach, with more technical problems due to staining variations, patient and control sera were directly labeled with the fluorochromes $\mathrm{Cy} 3$ and $\mathrm{Cy} 5$, respectively, and the resulting color (green, red, or yellow for the addition of both) was assayed, as in other arrays.

\section{Comments}


Using tiny amounts (as low as 0.2 ?1) of serum, autoantigen microarrays are a powerful tool to investigate the often complex autoantibody pattern of rheumatic (and other autoimmune) diseases. The authors of this paper mention several possible scientific applications of the new technique, including the assessment of epitope spreading, investigations of the role of immunoglobulin isotypes or testing for novel autoantigens. They also discuss a possible role in clinical decision making through better knowledge of the consequences of different autoantibody patterns, as well as a major role in diagnostic screening. The latter point is of tremendous economic interest. Indeed, such tests may be very helpful if the autoantibody patterns derived distinguish between significant autoantibodies and irrelevant findings. Otherwise, cheap and simple all-antigen testing may increase a present diagnostic problem; if high throughput testing leads to high numbers of false positive results, unacceptable frequencies of additional diagnostic tests could be a costly consequence.

\section{Methods}

Roboter-fabricated autoantigen arrays, ELISA

\section{References}

1. Robinson WH, DiGennaro C, Hueber W, Haab BB, Kamachi M, Dean EJ, Fournel S, Fong D, Genovese MC, de Vegvar HE, Skriner K, Hirschberg DL, Morris RI, Muller S, Pruijn GJ, van Venrooij WJ, Smolen JS, Brown PO, Steinman L, Utz PJ : Autoantigen microarrays for multiplex characterization of autoantibody responses. Nature Medicine . 2002, 8: 295-301.

This PDF file was created after publication. 